\title{
Circulating adhesion molecules ICAM-1, E-selectin, and von Willebrand factor in Henoch-Schönlein purpura
}

\author{
Oğuz Söylemezoğlu, Nedim Sultan, Turkiz Gursel, Necla Buyan, Enver Hasanoğlu
}

\begin{abstract}
Adhesion molecules play an important part in leucocyte transendothelial migration and thus may provide a useful marker of surface expression at inflammatory sites. In 20 patients with HenochSchönlein purpura serum intercellular adhesion molecule 1 (ICAM-1), E-selectin, and plasma von Willebrand factor (vWF) were determined by ELISA during the active and inactive phase of the disease. Twelve healthy children were studied as a control group. Serum ICAM-1 concentrations increased during the active phase of the disease and differed significantly compared with the inactive phase $(p<0.05)$. However ICAM-1 in the active phase did not differ significantly compared with controls $(p=0.08)$. Serum E-selectin concentrations did not differ in the active and inactive phase of the disease. By contrast, vWF increased in the active phase of the disease and differed significantly compared with inactive disease and control groups $(p<0.01)$. Considering the adhesion molecules and VWF, only vWF correlated well with the $C$ reactive protein measurement in the active phase, which is considered a good marker of disease activity. These data suggest that plasma vWF is a good marker of vascular inflammation and endothelial damage. Circulating ICAM-1 might be an additional parameter in some of the patients. (Arch Dis Child 1996;75:507-511)
\end{abstract}

Keywords: adhesion molecules, Henoch-Schönlein purpura, vasculitis, von Willebrand factor.

Leucocytes are prominent in the vascular inflammation of vasculitic syndromes like polyarteritis nodosa, Kawasaki disease, Wegener's granulomatosis, and Henoch-Schönlein purpura. The upregulation and enhanced expression of cytokine inducible cell surface adhesion molecules on polymorphonuclear leucocytes and on the normally non-adhesive vascular endothelium leads to the adherence of inflammatory cells to the vessel wall, their activation, and subsequent extravasation. The adhesion of leucocytes to endothelium and their transmigration across endothelium is dependent on cell adhesion molecules including intercellular adhesion molecule 1 (ICAM-1), vascular cell adhesion molecule 1 (VCAM-1), and E-selectin. ${ }^{1}$ ICAM-1 is constitutively expressed on both endothelial and circulating cells including leucocytes and is upregulated by immune activation and inflammation. E-selectin is found only on activated endothelium and binds to granulocytes, monocytes, and some memory $\mathrm{T}$ cells. ${ }^{2}{ }^{3} \mathrm{E}$-selectin appears to be a more specific marker of endothelial cell activation, being produced by activated endothelium. Raised concentrations of soluble forms of ICAM-1, VCAM-1, and E-selectin have been found in the sera of patients with a variety of disorders including Wegener's granulomatosis, systemic lupus erythematosus, $\mathrm{Ka}$ wasaki disease, and chronic inflammatory liver disease. ${ }^{4-7}$

High circulating concentrations of von Willebrand factor (VWF) have been also proposed as a marker for endothelial cell damage. ${ }^{8}$ As vWF release is enhanced by damage to endothelial cells, it has been demonstrated that circulating concentrations of vWF are increased in many diseases involving endothelial damage. Increased vWF was reported in different vasculitic syndromes including scleroderma, Kawasaki disease, haemolytic uraemic syndrome, and vasculitis in general ${ }^{9-11}$

Henoch-Schönlein purpura is the most common vasculitis syndrome of childhood and is also described as leucocytoclastic vasculitis. Clinical symptoms are characterised by abdominal pain, rash, arthralgia, and haematuria. The exact cause of Henoch-Schönlein purpura is unknown and several theories concerning the pathogenesis have been proposed. Circulating immune complexes containing IgA are detected in the serum of patients as well as immune complexes containing $\mathrm{C} 3$ and $\operatorname{IgA}$ are also found in the skin, intestines, and kidneys. ${ }^{12} 13$

These findings support the view that Henoch-Schönlein purpura is mediated by immune complexes. In recent years, there has been an increased number of studies characterising a spectrum of antineutrophil cytoplasmic antibodies (ANCA) associated with systemic vasculitis syndromes. The role of ANCA in the pathogenesis of Henoch-Schönlein purpura and IgA nephropathy was suggested in one study, however recent studies did not confirm these findings. ${ }^{14-16}$

The present study was designed to assess whether increased concentrations of circulating ICAM-1, E-selectin, and vWF are present in patients with Henoch-Schönlein purpura when compared with healthy children. Furthermore, we aimed to determine whether 
Table 1 Clinical findings and $C$ reactive protein during patient admission

\begin{tabular}{|c|c|c|c|c|c|c|}
\hline Patient No & Purpura ${ }^{*}$ & $\begin{array}{l}\text { Arthralgial } \\
\text { arthritis }\end{array}$ & Abdominal pain & $\begin{array}{l}\text { Gastrointestinal } \\
\text { bleeding }\end{array}$ & $\begin{array}{l}\text { Haematurial } \\
\text { proteinuria } \dagger\end{array}$ & $\begin{array}{l}\text { C reactive protein } \\
(\mathrm{mg} / \mathrm{l})\end{array}$ \\
\hline 1 & ++ & - & + & + & $-1-$ & 52 \\
\hline 2 & +++ & - & - & - & $-1-$ & 25 \\
\hline 3 & ++ & + & + & - & $-1-$ & 15 \\
\hline 4 & +++ & - & + & + & $++1-$ & 40 \\
\hline 5 & + & + & + & - & $+++1+$ & 47 \\
\hline 6 & ++ & - & + & + & $+1+$ & 60 \\
\hline 7 & +++ & - & - & - & $-1-$ & 86 \\
\hline 8 & ++ & + & + & - & $-1-$ & 40 \\
\hline 9 & +++ & - & + & - & $-1-$ & 15 \\
\hline 10 & + & - & - & - & $+1+$ & 15 \\
\hline 11 & ++ & + & - & - & $-1-$ & 30 \\
\hline 12 & + & + & + & - & $-1-$ & 30 \\
\hline 13 & ++ & $+1+$ & - & - & $-1-$ & 25 \\
\hline 14 & +++ & - & + & - & $-1-$ & 37 \\
\hline 15 & ++ & $+1+$ & - & - & $-1-$ & 110 \\
\hline 16 & +++ & + & + & + & $+1-$ & 75 \\
\hline 17 & +++ & + & + & + & $++1+$ & 150 \\
\hline 18 & +++ & - & + & + & $++1+$ & 190 \\
\hline 19 & + & - & - & - & $+++1-$ & 18 \\
\hline 20 & +++ & - & + & + & $+1-$ & 34 \\
\hline
\end{tabular}

$\star$ The severity of purpura: mild + , moderate ++ , severe.++++ Strip test for haematuria and proteinuria: for haematuria $($ erythrocytes $/ \mu \mathrm{l}),+<25,++25-80,+++80-200$; for proteinuria $(\mathrm{g} / \mathrm{l})+>0.30,++>100$.

measurement of serum concentrations of adhesion molecules might provide an effective method to monitor disease activity in patients with Henoch-Schönlein purpura. To investigate this we studied the circulating concentrations of ICAM-1 and E-selectin and compared the results with plasma $\mathrm{vWF}$ and $\mathrm{C}$ reactive protein in the patients with Henoch-Schönlein purpura.

\section{Patients and methods}

Twenty children ( 11 boys and nine girls; median age 9.3 years, range 3.0-15.0 years) with Henoch-Schönlein purpura diagnosed according to the American College of Rheumatology criteria ${ }^{17}$ were studied. The study included only the patients who had the initial presenting phase of the disease. Palpable purpura, abdominal pain, gastrointestinal bleeding, haematuria, and arthralgia were observed in the active phase of the disease (table 1). Duration of the symptoms varied from two to seven days and none of the patients was taking any drugs at the time of admission. During the follow up period the disease was considered inactive when the patient was symptom free. Leucocytoclastic vasculitis of small vessels was also confirmed in skin biopsy specimens of all six patients who had a biopsy. Serum samples were collected from patients at the time of diagnosis and at the time when the disease was considered inactive based on clinical criteria. Samples were stored at $-70^{\circ} \mathrm{C}$. Twelve age matched healthy children (median age 9.1 years, range 3.2-14.8 years ) were studied as controls. All of the children in the control group were healthy, afebrile, and on no medication during the study. The study was approved by the ethics committee of the university.

ASSAY METHODS

Adhesion molecules

Circulating ICAM-1 and E-selectin concentrations were measured using a commercially available ELISA kit (Bender-Med Systems, Vienna, Austria). Samples were diluted 1:10 for the soluble ICAM-1 assay and 1:5 for the soluble E-selectin assay. In brief, microtitre wells coated with antihuman soluble ICAM or E-selectin, were incubated with diluted samples, standards, and controls. In the second step horseradish peroxidase conjugated monoclonal antibody aganist ICAM or E-selectin was added. Unbound enzyme conjugated antiICAM-1 or anti-E-selectin was removed by washing and the substrate solution was added to reactive horseradish peroxidase. The reaction was terminated by the addition of sulphuric acid and absorbances were measured at 450 $\mathrm{nm}$. The ICAM-1 or E-selectin concentrations were determined from the standard curve.

\section{$v W F$}

Circulating vWF was assayed by a commercially avaliable ELISA kit (Asserochrom vWF, Diagnostica Stago, France). A microtitre plate coated with specific rabbit antihuman vWF antibodies captures the vWF to be measured in the plasma and then rabbit anti-vWF antibody coupled with peroxidase bind to remaining free antigenic determinants of vWF, forming the 'sandwich'. The bound enzyme peroxidase is then revealed by its activity on the substrate orthophenylenediamine in the presence of hydrogen peroxidase. After stopping the reaction with acid, the plate is read at $492 \mathrm{~nm}$ in an ELISA reader. Results are reported as per cent of normal plasma.

Plasma concentrations of $\mathrm{C}$ reactive protein were measured by immunoturbidimetry (Boehringer). Serum biochemistry was studied by autoanalyser (Technicon).

\section{STATISTICAL ANALYSIS}

The Mann-Whitney $U$ test was used for comparing the healthy children with patients. The significance of difference between patients with active and inactive disease were determined by the paired $t$ test. Linear regression analysis was used for correlation studies; $p$ values less than 0.05 were considered significant. Data were analysed using SPSS +PC and results are given as mean (SE). 
Table 2 Mean (SE) circulating adhesion molecules ICAM-1, E-selectin, vWF, and C reactive protein in Henoch-Schönlein purpura (HSP)

\begin{tabular}{lclcc}
\hline & Active HSP & Inactive HSP & Control \\
\hline ICAM-1 $(\mathrm{ng} / \mathrm{ml})$ & $432(35.2)$ & $295(2.7)$ & $306.6(33)$ \\
E-selectin $(\mathrm{ng} / \mathrm{ml})$ & $46.9(2.5)$ & $43(2.5)$ & $46.3(2.5)$ \\
vWF $(\%)$ & $206(16.5)$ & $127(10.2)$ & $107(9.1)$ \\
C reactive protein $(\mathrm{mg} / \mathrm{l})$ & $55(11)$ & $12(3)$ & $7 \quad(2.1)$ \\
\hline
\end{tabular}

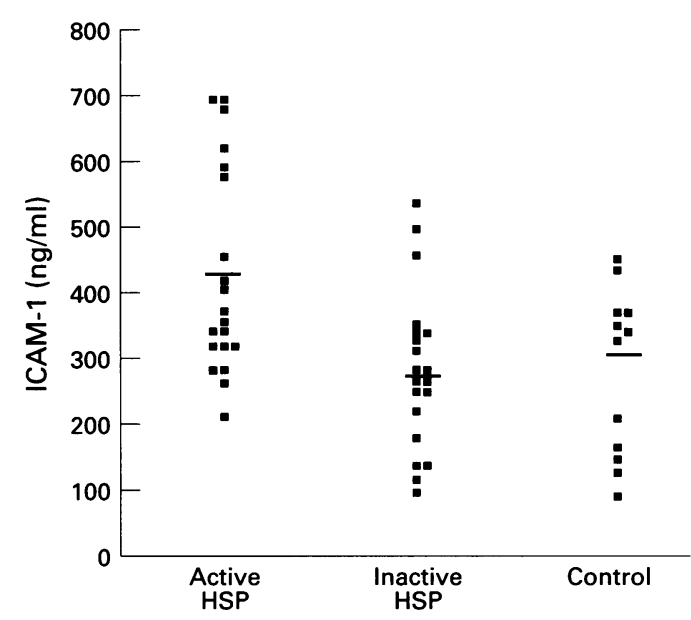

Figure 1 Serum ICAM-1 concentrations in the patient and control groups (HSP $=$ Henoch-Schönlein purpura).

\section{Results}

In the patients with active and inactive Henoch-Schönlein purpura mean circulating ICAM-1 concentrations were found to be 432 (35.2) $\mathrm{ng} / \mathrm{ml}$ and 295 (27) $\mathrm{ng} / \mathrm{ml}$ respectively (see fig 1). Serum ICAM-1 increased in nine $(45 \%)$ of the patients during the active phase. In healthy controls, ICAM-1 was found to be 306 (33) $\mathrm{ng} / \mathrm{ml}$. The mean serum ICAM-1 concentration during the active phase of the disease was significantly higher when compared with that in inactive disease $(p<0.05)$, but serum concentrations of ICAM-1 in the active phase did not differ significantly from those in the healthy controls $(\mathrm{p}=0.08)$ (table 2$)$.

The mean E-selectin concentrations in patients with Henoch-Schönlein purpura during the active and inactive phase were found to be $46.9(2.5) \mathrm{ng} / \mathrm{ml}$ and 43.8 (2.6) $\mathrm{ng} / \mathrm{ml}$ respectively. In the control group the E-selectin concentration was $45(3.8) \mathrm{ng} / \mathrm{ml}$. There was no significant difference between all these three groups regarding the serum E-selectin.

In 16 of 20 patients vWF antigen increased during the active period of the disease with a mean vWF value of 206 (\% control) compared with $127.7(\%)$ in the inactive disease and with 107.0 (\%) in the control group (fig 2). There was a significant difference in vWF between those with active and inactive disease $(p<0.01)$ and also between those with active disease and controls $(p<0.01)$.

$C$ reactive protein was significantly higher in the patients with active disease: it was found to be $55 \mathrm{mg} / \mathrm{l}$ during flare up and $12 \mathrm{mg} / \mathrm{l}$ in the follow up period of inactive disease.

We attempted to investigate the patients in two subgroups: those with systemic involvement, such as gastrointestinal bleeding and renal involvement, and those without. The serum and plasma concentrations of adhesion molecules ICAM-1, E-selectin, $\mathrm{C}$ reactive pro-

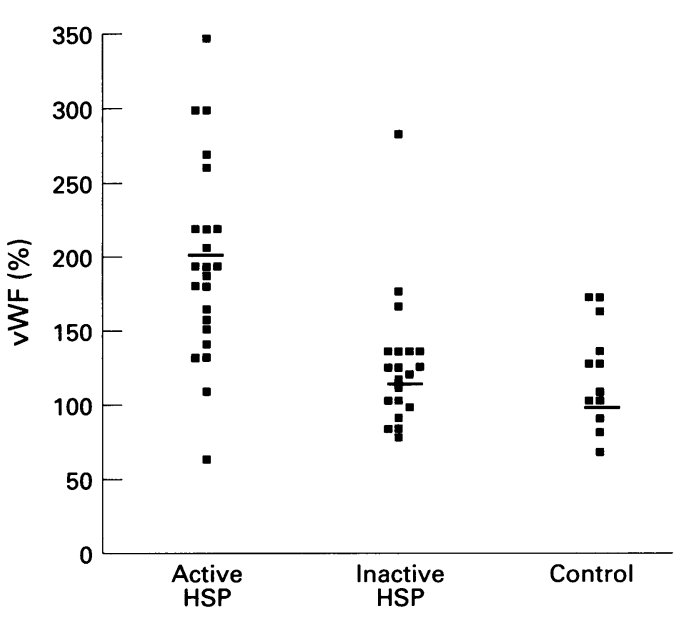

Figure 2 Plasma $v W F$ concentrations in the patient and control groups (HSP = Henoch-Schönlein purpura).

tein, and vWF did not differ significantly in these subgroups.

Between all these parameters there was a significant correlation between $\mathrm{C}$ reactive protein and vWF $(p<0.05)$. No correlation was found between ICAM-1, E-selectin, and C reactive protein and there was also no correlation between adhesion molecules and vWF.

Serum blood urea nitrogen and creatinine were all within normal limits in the patient and control groups.

\section{Discussion}

We found increased concentrations ( $>400$ $\mathrm{ng} / \mathrm{ml}$ ) of circulating ICAM-1 in $45 \%$ of the patients with active Henoch-Schönlein purpura. Although the serum ICAM-1 concentrations in this group differed significantly compared with patients with inactive disease, it did not differ significantly when compared with the control group. We found the highest concentrations of ICAM-1 in three patients $(699 \mathrm{ng} / \mathrm{ml}$, $688 \mathrm{ng} / \mathrm{ml}$, and $580 \mathrm{ng} / \mathrm{ml}$ ) who had renal involvement with haematuria and/or proteinuria. On the other hand the highest ICAM-1 concentration $(700 \mathrm{ng} / \mathrm{ml}$ ) was found in a patient who had severe purpura without renal involvement. We did not find increased E-selectin concentrations in either of the patient groups.

In different forms of vasculitis such as systemic lupus erythematosus, Wegener's granulomatosis, Kawasaki disease, and microscopic polyarteritis increased serum concentrations of circulating ICAM-1 and or E-selectin were reported. ${ }^{4-718}$ Circulating ICAM-1 was initially expected to be a promising inflammatory activity in different diseases. Although ICAM-1 is widely distributed, E-selectin is specific to endothelial cells and only minimally expressed in the resting state. ${ }^{19}$ Jeng et al reported higher concentrations of ICAM-1 in patients with systemic vasculitis than in those with cutaneous vasculitis. ${ }^{20}$ Furukawa et al suggested that serum ICAM-1 concentrations were an important immunological parameter for the severity of vascular damage during acute Kawasaki disease but in the same study they found no increment of serum ICAM-1 in the patients with anaphylactoid purpura. ${ }^{21}$ 
There are conflicting reports regarding serum ICAM-1 concentrations in vasculitic syndromes. John et al concluded that circulating ICAM-1 concentrations are not useful to define disease activity to indicate a clinical relapse in vasculitis or as a guideline for immunosuppressive treatment. ${ }^{22}$ Janssen et al also reported that soluble (s) ICAM-1 and E-selectin concentrations did not reflect the disease activity in either systemic lupus erythematosus or vasculitis. ${ }^{23}$ Circulating adhesion molecules were found to be higher in normal children than in adults and Nash et al showed that sE-selectin, sICAM-1, and sVCAM-1 all fell significantly over the age range in normal children. ${ }^{24}$ This study highlighted the need for the age matched controls, and the data from our study confirm these findings.

E-selectin is found only on activated endothelium in contrast to other adhesion molecules and can be detected in the blood as a soluble form, shed from the cell membrane, and could be used as an index of severity of vasculitis in inflammatory diseases. In the present study E-selectin concentrations did not differ significantly in the three groups and the data did not suggest E-selectin as a good parameter in Henoch-Schönlein purpura. Various circulating E-selectin concentrations have been reported in different forms of vasculitic syndromes. Nash et al found high circulating E-selectin and ICAM-1 concentrations in Kawasaki disease and they also reported increased vWF in these patients. ${ }^{18} \mathrm{Kim}$ and Lee found higher concentrations of E-selectin in Kawasaki disease but not in patients with Henoch-Schönlein purpura. ${ }^{25}$ Voskuyl et al found increased concentrations of circulating ICAM-1 and ICAM-3 but not E-selectin in patients with rheumatoid vasculitis. ${ }^{26}$ Some of these studies supported our findings and suggested that circulating adhesion molecule expression is more prominent in the medium sized vasculitis. Bradley et al demonstrated increased expression of ICAM-1 and E-selectin in the skin biopsy specimens of vasculitis patients of different forms including Henoch-Schönlein purpura and neutrophil infiltration was only found in the presence of E-selectin. Expression of E-selectin was thought to persist in the skin and act as a homing receptor for neutrophils and lymphocytes. ${ }^{27}$

We found higher concentrations of vWF in the acute phase of the disease that was significantly different from the inactive disease and control groups and correlated well with the high $C$ reactive protein. Sixteen of 20 patients had increased concentrations of vWF in the active phase. The other four patients who had normal concentrations of vWF had no signs of systemic involvement and a mild form of vasculitis was restricted to the skin. vWF is an adhesive multimeric glycoprotein synthesised by megakaryocytes and endothelial cells isolated from large and small veins, capillaries, the aorta, and arteries. ${ }^{28}{ }^{29}$ Nash et al reported high concentrations of vWF in febrile patients with infectious disease and they suggested high vWF were mainly due to the acute phase reaction. ${ }^{18}$
In the present study we did not have another control group with febrile children to compare with the patient group. In recent years various authors have reported an increase of VWF in the plasma of different vasculitic syndromes. ${ }^{930}$ Increased $\mathrm{vWF}$ concentrations are regarded as a reliable index of vascular damage and high concentrations of $\mathrm{vWF}$ have been proposed to be a specific marker for endothelial damage. ${ }^{31}{ }^{32}$

In conclusion, we have shown that plasma vWF antigen concentration increased in children with active Henoch-Schönlein purpura and these raised values most likely reflect increased amounts of vWF. However vWF concentrations are an indirect measurement of the endothelial cell damage; high concentrations can therefore reflect the activation or damage. The study indicated the importance of monitoring vWF concentrations as a useful marker of the severity of vasculitis. Our data also revealed that although some patients may have high concentrations of ICAM-1, monitoring of circulating ICAM-1 and E-selectin is not as useful as VWF in indicating disease activity and severity in Henoch-Schönlein purpura. Detection of adhesion molecules in the damaged vessels may shed light on the pathogenesis of the disease.

We wish to thank Professor A M El Nahas (Sheffield) for help with the manuscript and T Bagci (Public Health Department, Hacettepe, Ankara) for statistical assistance. This study was partly supported by the Gazi University Research Foundation.

1 Springer TA. Adhesion receptors of the immune system. Nature 1990;346:425-34.

2 Hemler ME, Huang C, Takada Y, Schwarz L, Strominger $\mathrm{JL}$, Clabby ML. Characterisation of the cell surface heterodimer VLA-4 and related peptides. $f$ Biol Chem 1987;262:1 1478-85.

3 Picker LJ, Kishimoto TK, Smith CW, Warnock RA, Butcher EC. ELAM-1 is an adhesion molecule for skin-homing T-cells. Nature 1991;349:796-9.

4 Cush JJ, Rothlein R, Lindsley HB, Mainolfi EA, Lipsky PE. Increased levels of circulating intercellular adhesion molecule-1 in the sera of patients with rheumatoid athritis.. Arthritis Rheum 1993;36:1098-102.

5 Mrowka CH, Sieberth HG. Detection of circulating adhesion molecules ICAM-1, VCAM-1, and E-selectin in Wegener's granulamatosis, systemic lupus erythematosus and chronic renal failure. Clin Nephrol 1995;43:288-96.

6 Carson CW, Beall LD, Hunder GG, Johnson CM, Newman W. Serum ELAM-1 is increased in vasculitis, scleroderma and systemic lupus erythematosus. F Rheumatol 1993;20: 809-20.

7 Gearing AJH, Newman W. Circulating adhesion molecules in diseases. Immunol Today 1993;14:506-12.

8 Anonymous. Factor Vlll related antigen and vasculitis [Editorial]. Lancet 1988;i:1203-4.

9 Ates E, Bakkaloglu A, Saatci U, Soylemezoglu O. Von Willebrand factor antigen compared with other factors in vascubrand factor antigen compared with other factors
litic syndromes. Arch Dis Child 1994;70:40-3.

10 Kahaleh MB, Osborn I, Leroy EC. Increased factor Vlll, von Willebrand factor antigen and von Willebrand factor activity in scleroderma and Reynaud's phenomenon. Ann Intern Med 1981;94:482-4.

11 Rose PE, Enayat SM, Sunderland R, Short PE, William CE, Hill FGH. Abnormalities of factor Vlll related multimers in the hemolytic uremic syndrome. Arch Dis Child 1984;59: 1135-40.

12 Jones CL, Powell HR, Kincaid-Smith P, Robertson DM. Polymeric IgA and immune complex concentrations in IgA-related renal disease. Kidney Int 1990;38:323-31.

13 Saulsbury FT. Heavy and light chain composition of serum IgA rheumatoid factor in Henoch-Schönlein purpura. Arthritis Rheum 1992;35:1377-80.

14 Van Del Wall Bake A, Lobatto S, Jonges L. IgA antibodies directed aganist cytoplasmic antigens of polymorphonudirected aganist cytoplasmic antigens of polymorphonu-
clear leucocytes in patients with Henoch-Schönlein purclear leucocytes in patients with Henoch-S
pura. Adv Exp Med Biol 1987;216:1593-8.

15 O'Donoghue DJ, Nusbaum P, Noel LH, HalbwachsMecarelli L, Lesavre PH. Antineutrophil cytoplasmic antiMecarelli L, Lesavre PH. Antineutrophil cytoplasmic anti-
bodies in IgA nephropathy and Henoch-Schönlein purbodies in IgA nephropathy and Henoch-S
pura. Nephrol Dial Transplant 1992;7:534-8.

16 Robson WL, Leung AK, Woodman RC. The absence of antineutrophil cytoplasmic antibodies in patients with Henoch-Schönlein purpura. Pediatr Nephrol 1994;8:295-8. 
17 Mills JA, Michel BA, Block DA, et al. The American College of Rheumatology 1990 criteria for the classification of HenochSchönlein purpura. Arthritis Rheum 1990;33:1114-21.

18 Nash MC, Shah V, Dillon MJ. Soluble cell adhesion molecules and von Willebrand factor in children with Kawasaki disease. Clin Exp Immunol 1995;101:13-7.

19 Carlos TM, Harlan JM. Leucocyte-endothelial adhesion molecules. Blood 1994;84:2068-70.

20 Jeng GW, Wang GR, Liu MF, et al. Measurement of anti-endothelial, anticardiolipin autoantibodies and intercellular adhesion molecules- 1 in patients with systemic and cutaneous vasculitis. Chinese fournal of Microbiology and Immunology 1993;26:86-93.

21 Furukawa S, Imai K, Matsubara T, et al. Increased levels of intercellular adhesion molecule-1 in Kawasaki disease. Antercellular adhesion molecule-1 in Kawasaki disease.

Arthritis Rheum 1992,35:672-6.

John S, Nuemayer HH, Weber M. Serum circulating ICAM-1 levels are not useful to indicate active vasculitis or early renal allograft rejection. Clin Nephrol 1994;42:369-75.

23 Janssen BA, Lumani RA, Gordon C, et al. Correlation of blood levels of soluble vascular cell adhesion molecule- 1 with disease activity in systemic lupus erythematosus and vasculitis. Br f Immunol 1994;33:1112-6.

24 Nash MC, Wade AM, Shah V, Dillon MJ. Normal levels of soluble E-selectin, soluble intercellular adhesion molecule-1 (sICAM-1), and soluble vascular cell adhesion molecule-1 (sVCAM-1) decrease with age. Clin Exp Immunol 1996;103:167-70.
$25 \mathrm{Kim}$ DS, Lee KY. Serum soluble E-selectin levels in Kawasaki disease. Scand $\mathcal{F}$ Rheumatol 1994;23:283-6.

26 Voskuyl AE, Martin S, Melchers I, Zwinderman AH Weichselbraun I, Breedweld FC. Levels of circulatingintercellular adhesion molecule- 1 and 3 but not circulating endothelial leucocyte adhesion molecule are increased in patients with rheumatoid vasculitis. $\mathrm{Br} f$ Rheumatol patients with

27 Bradley JR, Lockwood CM, Thiru S. Endothelial cell activation in patients with systemic vasculitis. $Q \mathcal{F ~ M e d}$ 1994;87:741-5.

28 Sporn LA, Chauin SI, Marder VJ, Wagner DD. Biosynthesis of von Willebrand protein by human megakaryocytes. $\mathcal{f}$ Clin Invest 1985;76:1102-6.

29 Jaffe EA, Hoyer LW, Nachmann RL. Synthesis of von Willebrand factor by cultured human endothelial cells. Proc Natl Acad Sci US A 1974;71:1906-9.

30 Nusinow SR, Federici AB, Zimmerman TS, Curd JG. Increased von Willebrand factor antigen in the plasma of patients with vasculitis. Arthritis Rheum 1984;27:1405-10.

31 Woolf AD, Wakerley G, Wallington TB, Scott DGI, Dieppe PA. Factor Vlll related antigen in the assessment of vasculiPA. Factor Vlll related antigen in the
tis. Ann Rheum Dis 1987;46:441-7.

32 Bowyer SL, Ragsdale CG, Sullivan DB. Factor Vlll related antigen and childhood rheumatic diseases. $\mathcal{f}$ Rheumatol 1989;16:1093-7. 